\title{
GÊNERO E A DISTÂNCIA ENTRE A INTENÇÃO E O GESTO
}

\section{Clara Araújo Celi Scalon}

\section{Apresentação}

Este artigo tem por objetivo apresentar alguns resultados da pesquisa "Gênero, Trabalho e Família no Brasil", baseada num survey realizado no final de 2003, com uma amostra representativa da população brasileira. ${ }^{1}$ O survey fez parte de uma pesquisa internacional que o ISSP - International Social Science Program - conduziu com o intuito de identificar as transformações que vêm sendo operadas nas relações de gênero, tendo por base as dinâmicas de conciliação entre a vida familiar e o trabalho pago. A pesquisa procurou investigar as percepções que mulheres e homens têm acerca dessa conciliação e envolveu aspectos relacionados com o exercício da maternidade e da paternidade; a conjugalidade, a divisão do trabalho

Artigo recebido em janeiro/2005

Aprovado em abril/2006 doméstico e a satisfação com a vida familiar e com o trabalho. Um conjunto de questões dirigidas especificamente aos inquiridos que viviam conjugalmente buscou captar as percepções desses indivíduos sobre a divisão do trabalho doméstico, por meio de perguntas sobre tarefas domésticas e atividades com os filhos.

Em trabalhos anteriores (Araújo e Scalon, 2004 e 2005) foram apresentados os resultados mais gerais dessa pesquisa. Neste artigo, selecionamos as questões que consideramos mais diretamente associadas à problemática da conciliação entre família e trabalho pago para tentar responder às seguintes perguntas: A presença das mulheres no mercado de trabalho vem alterando as práticas tradicionais de divisão sexual do trabalho na família, de modo que se possa falar de relações de gênero mais igualitárias no Brasil? Há correspondência entre as percepções e os valores expressos pelos inquiridos, sobre o trabalho das mulheres, atribuições de homens e mulheres na 
esfera da família e do casamento e as suas atitudes $^{2}$ no cotidiano doméstico das tarefas envolvidas na reprodução e no cuidado com os filhos?

Na primeira parte, à luz de uma sucinta análise descritiva, apresentamos os traços centrais das percepções dos entrevistados sobre a igualdade de gênero e a conciliação entre trabalho pago e vida familiar. ${ }^{3}$ Em seguida, analisamos como algumas práticas domésticas envolvidas nessa conciliação são conduzidas no cotidiano de casais entrevistados. A segunda parte procura estabelecer possíveis correlações entre os diferentes fatores que influenciam as percepções, os valores e as práticas reportadas pelos entrevistados, a partir do uso de análises multivariadas. Por fim, concluímos indicando os principais traços que se apresentam no Brasil atualmente em relação ao tema.

\section{Perfil da população estudada}

De forma breve, apresentamos alguns dados gerais que permitem caracterizar a amostra em estudo. A média de idade é de 39 anos. A escolaridade é baixa: $67,8 \%$ só chegaram ao primeiro grau e apenas $10 \%$ ao terceiro grau, sendo que apenas $6 \%$ tinham concluído o terceiro grau. Quanto à cor ou etnia, 46,3\% definiram-se como branca, $11,2 \%$, como preta, 37,6\%, como parda, $1,9 \%$, como amarela, e 3,1\%, como indígenas. Entre os entrevistados, $45 \%$ declararam-se chefes de família e $26 \%$, cônjuges. Quanto ao sexo, declararam-se chefes de família $68 \%$ dos homens e 32\% das mulheres. Entre os respondentes, 59,4\% disseram ter menos de 17 anos residindo no domicílio. Por sexo, considerando também as pessoas que se disseram desempregadas há mais de doze meses, $53,9 \%$ das mulheres foram incluídas na categoria de ativas, 30,5\% definiram-se como "do lar" e $11,3 \%$, como aposentadas. Entre os homens esses percentuais foram, respectivamente, de $81 \%, 0,6 \%$ e $13,6 \%$. Ao contrário do que se costuma dizer, a jornada semanal de trabalho é alta: 59\% dos entrevistados trabalham mais de 40 horas. Entre as mulheres, 30,2\% trabalham até 30 horas, 23\% entre 30 e 40 horas semanais e $46,6 \%$ trabalham mais de 40 horas. Entre os homens, esses percentuais são, respectivamente, de 14,2\%, 18,7\% e 67.1\%. Quanto à condição conjugal, 63,8\% do total da amostra vivia conjugalmente no momento da pesquisa, categoria definida pela soma dos que se declararam casados e não-casados, estes últimos vivendo com alguém. Apenas em 7,6\% dos domicílios havia empregada doméstica.

Já o perfil religioso revela o que outras pesquisas já vêm apontando: embora a maioria da população seja católica $(75,2 \%)$, tem crescido a proporção de evangélicos na população $(13,7 \%)$, o que parece ser maior entre as mulheres.

\section{Gênero e família: tendências recentes}

As mudanças na característica dos arranjos conjugais em termos de composição e de configuração afetiva vêm sendo analisadas por uma vasta literatura (Gornick e Mayers, 2004; Torres, 2001, 2002, 2004; Bozón, 2004; Aboim e Wall, 2002; Castells, 2000; Jelin, 1995; Vaitsman, 1994). Em geral, essas análises apontam para uma profunda alteração dos padrões de organização familiar no que diz respeito à extensão da família, com a redução de seu tamanho; nos padrões de conjugalidade, com o aumento de famílias monoparentais e de casais compostos do mesmo sexo; com maior plasticidade das relações e o afeto se tornando elemento central que orienta a constituição das relações amorosas e da conjugalidade; e há ainda um enfraquecimento do patriarcado como referência hierárquica e de poder, embora este aspecto seja bastante polêmico. Tais mudanças, decorrentes também do ingresso maciço das mulheres no mercado de trabalho, apontam para evidências de que os modelos de conciliação entre trabalho pago e vida familiar baseados na clássica dupla "homem provedor" e "mulher cuidadora" vêm sendo alterados em direção a um modelo dual, no qual as mulheres permanecem como as principais "cuidadoras", mas o trânsito entre o espaço doméstico e público se constitui um dado contemporâneo.

Importa ressaltar que essas dinâmicas de conciliação são também mediadas pela centralidade crescente que o mercado adquire na vida social contemporânea (Dedecca, 2004; Gornick e Mayers, 2004), ou seja, por imperativos estruturais e não apenas internos às relações familiares. Trata-se também de processo e transições globais, embora 
a intensidade varie de acordo com as culturas e os contextos (Norris e Inglehart, 2003; Hirata, 2002).

Muitas dessas tendências, que se apresentam mais ou menos intensas nos diferentes países de acordo com os contextos específicos, têm operado favoravelmente sobre as mulheres, ao mesmo tempo em que decorrem, também, das mudanças nas suas posições em outras esferas, sobretudo no âmbito do trabalho. No caso do Brasil, um aspecto que merece destaque particular é o que se refere ao tamanho e à composição das famílias (Berquó, 2002). Embora não existam muitos estudos longitudinais, a análise de alguns trabalhos mais históricos sugere que a intensificação do ingresso das mulheres no mercado de trabalho a partir da década de 1970 contribuiu para essa uma mudança substancial nos arranjos familiares no país.

De fato, diante do cenário de algumas décadas atrás, o sentido de ruptura que muitas dessas mudanças adquirem é maior para mulheres. Isso, contudo, não define a natureza das relações como menos conflitantes. Como salientaram Torres et al. (2002), os espaços familiares são lugares onde circulam e são geridos bens materiais e simbólicos que nem sempre são passíveis de consensos entre seus pares. Não só a individuação abre espaço para maiores demandas pessoais, como também as condições de uso e de acesso aos recursos tendem a ser objeto de conflitos.

Em contrapartida, as relações intrafamiliares não são apenas derivadas dos sentidos subjetivos conferidos por seus membros ou ainda pela dinâmica interna ao ambiente doméstico. Elas são mediadas também por aspectos exógenos, decorrentes dos modos de organização da vida pública e dos lugares em que os indivíduos ocupam e disputam nessas esferas. As dinâmicas organizacionais e o acesso a determinados tipos de recursos têm impacto sobre a vida familiar e conjugal tanto quanto estas influenciam as disposições e as chances dos indivíduos na vida pública. Nesse caso, tais dinâmicas incidem de forma particular sobre a vida e as chances das mulheres, como tem sido demonstrado por inúmeros estudos empíricos. Ao contrário dos homens, as possibilidades de satisfação das mulheres, além dos imperativos externos próprios ao "mundo do trabalho", são mediadas, também, por suas condições internas à família. Um dos aspectos mais evidentes quando se analisam as relações entre família e espaço público é o de que "o doméstico" permanece como o principal elemento de mediação da vida das mulheres, mesmo que isso ocorra de forma involuntária. Por essa razão os aspectos "internos" à família - cuidado ou atividades de reprodução da vida doméstica -, assim como aspectos envolvendo as mulheres no mercado de trabalho necessitam ser observados, também, sob o prisma da interação entre esfera doméstica/familiar e esfera pública, problematizando-a em relação às articulações com o mercado e com o Estado, a exemplo de vários autores, como, por exemplo, Esping-Andersen (1990), Fraser (1999) e Crompton (1999), Gornick e Mayeres (2004), Torres (2004), Arriagada (2004), entre outros.

Nessas e em outras análises vem sendo ressaltado que as mulheres, diferentemente dos homens, estão sujeitas a dois tipos de dependência - do mercado e da família -, e isto tem impacto sobre sua autonomia e a forma como organizam e orientam suas ações. O grau de mediação do Estado, por sua vez, poderia ter efeitos mais ou menos positivos sobre tal dependência à intensidade do deslocamento: do modelo mais tradicional ou de rigidez de papéis - homem provedor/mulher cuidadora - em direção a modelos duais mais igualitários de conciliação, ainda que predominantemente marcados pelo desigual envolvimento de homens e mulheres com a vida doméstica.

Ao lado desses condicionantes, a cultura surge como relevante para pensar mudanças e recorrências nas dinâmicas envolvendo as relações de gênero e, com essa perspectiva, parecenos particularmente relevante para a compreensão dos dados do survey em exame o trabalho de Norris e Inglehart (2003). Esses autores incorporam fatores estruturais e culturais para estudar e explicar as variações nas atitudes em relação à igualdade de gênero, entre sociedades e entre homens e mulheres. Considerando as posições dos indivíduos e também as diferentes regiões geográficas para pensar as tradições culturais, os autores sugerem que a desigualdade/igualdade de gênero varia sistematicamente de acordo com o nível de desenvolvimento político e socioeconômico e os padrões religiosos e culturais de uma determinada sociedade. Em síntese, advogam que a modernização das sociedades implica o enfraquecimento dos papéis tradicionais baseados no gênero. A 
modernização traz consigo o ingresso das mulheres no mercado de trabalho, o que conduz a mudanças em diversos aspectos da vida social, na família e nas esferas públicas e no trabalho. As mudanças nos estilos de vida de homens e mulheres, especialmente na fase de desenvolvimento pós-industrial, geram, também, transformações inevitáveis em termos de valores culturais. Tais valores operam como impulsionadores decisivos de diferenças geracionais dentro das mesmas sociedades e também de diferenças de acordo com os diferentes níveis de desenvolvimento político e econômico.

Inglehart e Norris tomam como variáveis relevantes a idade, a educação, o rendimento, a participação no mercado, a religião (freqüência com que se vai à igreja), a condição de conjugalidade e a maternidade/paternidade. No âmbito dos países como um todo, consideram o desenvolvimento humano e o nível de democracia. Além disso, levam em conta a região geográfica como base de referência para as diferentes tradições culturais. Os autores concluíram que as mulheres tendem a ser ligeiramente mais abertas à igualdade de gênero do que os homens, mas as diferenças entre os sexos são menores do que as diferenças entre sociedades. Nesse caso, além dos indicadores de desenvolvimento socioeconômico e político, foram consideradas também os de diferentes tradições religiosas. Variáveis como educação, rendimento e participação no mercado de trabalho correlacionam positivamente com igualdade de gênero. Já a idade (ser mais idoso), a freqüência religiosa, a conjugalidade (ser casado) e possuir filhos correlacionam negativamente com posições de gênero mais igualitárias. Os autores concluem que existe um tipo de desigualdade de gênero moderna, denominada teoria de desalinhamento de gênero.

Há alguns problemas nessa teoria que, no espaço restrito deste artigo, não poderão ser discutidos devidamente. De qualquer maneira, são explicitados na própria designação teórica - "desalinhamento de gênero" -, termo que confere um sentido linear e progressivo às mudanças. Entretanto, esses problemas não retiram a validade do argumento central, qual seja, a igualdade e a desigualdade de gênero são mediadas por múltiplos fatores, particularmente a cultura, articulando dimensões socioeconômicas e culturais.
Neste trabalho, pretendemos verificar em que medida o gênero se mostra, em comparação com outras variáveis, relevante na constituição dos valores e das praticas que organizam a vida cotidiana das famílias no Brasil. Embora o conjunto de variáveis que podemos definir como "morais" ou culturais não seja muito grande, é possível reunir variáveis de "percepção" e de opinião, assim como fatores como religiosidade para pensar sobre a dimensão da cultura e sua relação com elementos socioeconômicos. Subjacente a este exercício, está a compreensão de que o processo de modernização - compreendido em suas dimensões estruturais e simbólicas - produz mudanças nas atitudes e nos valores culturais, mudanças que vêm apontando para uma igualdade de gênero.

\section{Os sentidos do trabalho doméstico para mulheres e homens}

Como foi discutido anteriormente, o trânsito entre a atividade de trabalho para remuneração e as atividades domésticas cotidianas é uma constatação entre a maioria das mulheres. Além de ser um imperativo de sobrevivência, o trabalho pago pode e tende a se constituir em aspiração de realização pessoal. Com efeito esse trânsito ocorre predominantemente entre as mulheres, da casa para o trabalho. Ao mesmo tempo, o domicílio e a família permanecem como espaços primordiais de reprodução material e de produção simbólica da vida cotidiana. Como então conciliar o desejado ou necessário trabalho da mulher com o fato concreto das atividades domésticas e a maternidade, e quais as dimensões que legitimam ou tencionam essa conciliação? As respostas às questões envolvendo a relação entre afeto materno, qualidade de vida familiar e trabalho pago, assim como aquelas relativas às aspirações individuais das mulheres, fornecem pistas interessantes a respeito das percepções de ambos os sexos sobre a maternidade e o lugar das mulheres. A análise dos dados contidos nas Tabelas 1 e 2 (Anexo 1) sugere que há uma elevada aceitação do trabalho como parte constitutiva da vida da mulher; maior entre as mulheres, mas igualmente elevada entre os homens. Como se observa, essa aceitação é acompanhada da permanência da valorização da 
domesticidade feminina, particularmente de seu aspecto maternal e, como se pode notar, isto ocorre, sobretudo, entre os homens. As respostas apontam para a valorização do trabalho, mas sugerem um outro aspecto, o da permanência ou da conciliação do espaço tradicional - a casa e a maternidade. Homens e mulheres concordam quanto à importância ou à necessidade do trabalho pago para as mulheres, mas não com a mesma intensidade. A percepção dos homens sobre o que querem as mulheres está mais associada à domesticidade do que a das próprias mulheres.

É sobretudo em relação aos filhos que a ausência feminina do espaço doméstico e a possibilidade de conciliação se mostram mais problemáticas para ambos, mas, sobretudo, entre os homens. É de se supor que, na percepção dos entrevistados, a ausência das mulheres tenderia a gerar certa carência de afeto, o que poderia estar associado ao tempo dedicado ao exercício da maternidade, e não à qualidade dessa relação.

$\mathrm{Na}$ Tabela 2, a centralidade da maternidade mais uma vez é revelada. A construção de uma outra identidade feminina ainda parece estar condicionada a esse lugar materno, sobretudo quando relacionado à fase em que os filhos são pequenos. Para os homens, porém, além do exercício da maternidade, o lugar de "esposa" também permanece relevante. Embora exista uma diferença razoável nas respostas de homens e mulheres quando se trata de trabalhar fora antes de ter filhos ou quando estes já freqüentam escolas ou saíram de casa, em se tratando dos filhos pequenos, há certo consenso entre ambos os sexos de que as mulheres não deveriam trabalhar em tempo integral nesse período. A conciliação com um trabalho que lhes permita desenvolver as atividades de cuidado dos filhos se constitui um ideal para parcela significativa das entrevistadas.

Os dados sugerem que, no âmbito dos valores, a afirmação de uma individualidade do sujeito e de autonomia para se movimentar nos espaços sociais tende a contrastar com uma identidade que se transforma de pessoa em esposa e mãe. Como veremos mais adiante, para as mulheres, essa tensão parece ser determinada não apenas por dimensões de valores, mas também por dimensões concretas de tempo. Nesse caso, a tensão remete a algo concreto: as cobranças quanto à dedicação sobretudo aos filhos e a necessidade de trabalho com fins de ganhos financeiros e/ou a dificuldade de um exercício profissional desprovido de outras atenções. Um olhar sobre as respostas masculinas indica que os homens permanecem valorizando mais uma identidade feminina marcada pelos papéis de esposa e de mãe, e suas expectativas acerca da relação conjugal tendem a ser mediadas por tais valores.

\section{Os homens e o trabalho doméstico}

Até que ponto, às percepções mais igualitárias sobre o acesso das mulheres ao trabalho e sua realização profissional como direito correspondem percepções menos tradicionais sobre o tipo de participação masculina na vida familiar e cotidiana? Em que medida ao já constatado trânsito das mulheres em uma direção - do doméstico para o público - corresponde um trânsito masculino em direção inversa? As respostas contidas na Tabela 3 permitem analisar as opiniões de homens e mulheres sobre a tradicional divisão sexual de papéis com o foco sobre os homens, quanto às tarefas domésticas e à figura de provedor.

A aceitação da idéia de divisão das despesas familiares é bastante elevada - 92,5\% dos homens e $93,6 \%$ das mulheres concordam totalmente ou em parte com a afirmação. A pergunta mais emblemática quanto à tradicional divisão de papéis é se o homem deve ganhar dinheiro enquanto as mulheres cuidam da casa (questão B). Embora os percentuais se reduzam bastante, é sintomático que $52,3 \%$ dos homens respondam que concordam com a tradicional divisão de papéis. É ainda surpreendente que encontremos $45 \%$ de mulheres que aceitem tal afirmação. Como defender a participação de ambos na renda e, ao mesmo tempo, a permanência dos papéis dicotômicos tais como são apresentados? As respostas sugerem a seguinte leitura: sobretudo entre os homens, permanece como percepção uma necessidade pragmática relacionada com a escassez orçamentária e uma idéia de trabalho que é aceita, mas com a conotação de "auxiliar", embora de fato não o seja. Essa percepção acompanha o aceite do trabalho feminino, mas este não necessariamente significa alterar as representações simbólicas e efetivas acerca dos 
lugares prioritários de homens e mulheres na condução da vida cotidiana. Em outras palavras, o trânsito permanece sob forte influência do tradicional modelo dual "homem provedor" e "mulher cuidadora", embora o primeiro pólo, de fato, já não seja mais predominante entre os arranjos.

Perceber o trabalho feminino como auxiliar não é um dado novo. Pesquisas pioneiras já apontavam para esses resultados (Bruschini, 1990; Hirata e Humphrey, 1986). Talvez, o que mereça destaque seja exatamente a sua permanência como um valor ainda forte, embora não mais predominante, e já com mais de $40 \%$ da PEA nacional sendo composta por mulheres. A permanência mais acentuada da idéia de provedor é confirmada pelas respostas à pergunta sobre qual a renda ideal para o homem. Enquanto 59\% das mulheres responderam ser aquela igual à da mulher, entre os homens esse percentual foi de $50 \%$. Por outro lado, $47,9 \%$ dos homens acham que devem ganhar mais do que as mulheres, mas entre elas há ainda uma parcela significativa $(38,3 \%)$ que concorda com tal afirmação. Merece destaque o fato de mulheres e homens apresentarem elevados índices de concordância quanto à necessidade de maior envolvimento masculino com os filhos e a divisão de tarefas domésticas. O cuidado dos filhos é o item mais acordado entre ambos os sexos. A divisão de tarefas domésticas já não obtém índices semelhantes, embora estes continuem elevados. Nesse caso, o corte de gênero é bastante nítido. São principalmente as mulheres que têm essa percepção mais igualitária da divisão de tarefas. Sem dúvida, não podemos considerar que no Brasil ainda estamos diante do homem tradicional e machista como costumamos pensar. Mas as faces de relações mais igualitárias e de relações mais tradicionais se mesclam e se evidenciam, indicando aspectos "modernos" e outros "conservadores" que revelam as ambigüidades da esperada modernização.

\section{O casamento como valor e aspiração de felicidade}

Considerando a tendência contemporânea à constituição de relações orientadas por escolhas afetivas, e não meramente pragmáticas ou baseadas em sentido de honra, analisaremos a seguir o lugar que os entrevistados conferem a algumas dessas escolhas na constituição de relações conjugais, na estruturação de famílias e no ideal de felicidade.

As respostas contidas na Tabela 4 apontam para as tendências de enfraquecimento institucional do casamento e valorização de conjugalidades centrada em satisfações individuais, com maiores margens de manobras para as mulheres. O dado mais importante a destacar é que, ao contrário do que costuma ser veiculado pelo senso comum, nesta pesquisa são as mulheres mais do que os homens que tendem a rejeitar o caráter formal e a concordar que não necessariamente o casamento constitui o ideal de felicidade. ${ }^{4}$ Essa tendência é constatada, também, em respostas que remetem ao que poderíamos definir como o sentido moral do casamento (questões E e F). Comparativamente, as mulheres tendem a aceitar mais que o casamento possa ser importante para a criação dos filhos, mas isso é condicionado a uma situação satisfatória individual de conjugalidade. Essas e outras questões apontam, portanto, que é nos espaços de relações afetivas e de escolhas que o individualismo, como valor moderno, que torna a vida pessoal "um projeto aberto, criando novas demandas e novas ansiedades" (Giddens, 1991, p. 83), se mostra mais evidente no contexto desta pesquisa.

\section{Valores "morais": autoridade, hierarquia e direitos individuais}

Seguindo o sentido proposto por Giddens (1991) quanto à "democratização da esfera privada" como projeto que está na ordem do dia, serão analisados brevemente ${ }^{5}$ alguns itens do bloco de questões que definimos com "valores morais". Esta designação deve-se ao fato de tais itens não estarem tão vinculados a compartilhamento, porém a direitos individuais em relação à sexualidade e a dimensões de autoridade e posse nas relações de gênero. O uso da autoridade e da punição como recurso de controle familiar é uma das características do modelo patriarcal de família que envolve, também, uma noção de fidelidade e obediência, implícitas na conjugalidade e percebidas como pertencimento ao outro. Por conta da tendência à 
maior simetria entre os membros da família, esperávamos que os inquiridos tendessem a recusar o uso da força como recurso de solução de conflitos. Considerando a hipótese de que gerações mais velhas - e, portanto, em geral, já fora do mercado - tenderiam a ser mais conservadores em relação a esses aspectos, selecionamos apenas aqueles que se definiram como ativos. A primeira coisa a destacar, conforme mostram alguns dos dados da Tabela 5, é que, nesta pesquisa, a maioria dos homens e das mulheres recusa o uso da punição ou da ameaça como forma de controle conjugal. Contudo, é de se notar que as mulheres tendem a ter posições ligeiramente mais modernas do que os homens, com percentuais mais elevados de recusa. Por outro lado, vale dizer que não é desprezível o percentual de mulheres, e, sobretudo, de homens, que ainda consideram válidos tais recursos, fato que, provavelmente, ajuda a explicar os elevados percentuais de registros sobre violência intrafamiliar e violência de gênero. Mas como tendência, tais respostas apontam um enfraquecimento da autoridade masculina e uma maior reciprocidade para com o "outro". Em se tratando do exercício da sexualidade, as respostas revelam posições mais abertas em relação aos direitos sexuais como escolha, e, mais uma vez, tais posições se encontram, principalmente, entre as mulheres. Contudo, em geral, sugerem que nesse aspecto as relações tendem a ser mais mediadas pelo desejo mútuo e não tanto pelo poder, embora também não se deva desconsiderar o percentual de mulheres e, sobretudo, de homens que ainda concebe o direito e a autoridade masculina como decisivas para que as relações aconteçam.

Entre as questões que definimos como "morais", o tema do aborto, sem dúvida, permanece como emblemático para o debate sobre valores modernos e relações de gênero, uma vez que remete ao direito individual das mulheres sobre o seu corpo e, ao mesmo tempo, está fortemente marcado por aspectos religiosos. Conforme supúnhamos, a Tabela 6 mostra que o aborto como uma questão de direito da mulher - itens A e E ainda é predominantemente rejeitado, e sua prática deve ser punida. Embora mais homens do que mulheres tendam a ser favoráveis à prisão, a recusa à idéia do direito da mulher tende a ser mais elevada entre as próprias mulheres. Em contrapar- tida, diante do tabu que o tema ainda exerce no país, os índices de concordância à questão E não podem ser desprezados, assim como os elevados índices de aceitação do aborto em casos de risco de vida da mãe e anomalia fetal.

\section{Homens e mulheres no cotidiano doméstico}

Como foi assinalado, as atividades relacionadas com a reprodução da vida e que envolvem a divisão de um conjunto de atividades necessárias à organização e ao funcionamento dos domić́lios, o cuidado com as crianças e o uso do tempo "livre", isto é, tempo de final de semana, formalmente reservado para o descanso, necessitam ser vistas sob o ângulo das mudanças culturais. Nesse sentido, englobam necessidades que vão sendo alteradas no tempo e no espaço. A reprodução da vida e como isso se realiza variam historicamente entre culturas e de acordo com os contextos socioeconômicos. Pensar como ocorre a divisão de trabalho doméstico implica considerar que as condições das ações dos indivíduos são mediadas por seus valores e escolhas, mas também pelos contextos estruturais e acesso a recursos, aspectos que devem ser contemplados como impulsionadores ou limitadores de determinadas tendências. Por outro lado, a análise da divisão do trabalho numa perspectiva de gênero mostra que esses fatores podem ser mais ou menos relevantes, porém, não são tão determinantes para alterar substantivamente a característica quase universal da divisão sexual do trabalho doméstico.

A Tabela 7 condensa o conjunto das atividades domésticas para as quais os entrevistados foram solicitados a responder. Os dados revelam que a divisão sexual do trabalho doméstico (sem considerar as crianças) ainda permanece amplamente dominada pelo padrão tradicional para ambos os sexos. Os homens só respondem por mais de $50 \%$ na atividade de pequenos consertos domésticos. Algumas atividades, como lavar e passar roupa e/ou cozinhar têm sido territórios praticamente inexplorados para os homens e assim parecem permanecer. Embora os percentuais se alterem em algumas circunstâncias, não são suficientes para indicar que o trabalho pago, 
mesmo com jornada integral, conduz a uma situação que possa ser considerada equilibrada na divisão das atividades domésticas, conforme os dados da Tabela 8.

\section{O "cuidado" e as atividades com as crianças}

Como assinalamos, o lugar do cuidado na vida das mulheres tem sido determinante sobre suas possibilidades de escolhas em relação à vida em geral. De fato, como observou Duran (2000), excluindo-se os limites biológicos relacionados à função da gestação, todos os outros aspectos envolvidos no cuidado podem ser efetivamente desenvolvidos por homens ou mulheres. Não é, entretanto, o que ocorre no cotidiano.

Na pesquisa, o cuidado pôde ser observado sob dois ângulos: referia-se aos familiares doentes (Tabela 7) e, sobretudo, ao envolvimento/compartilhamento com as atividades necessárias à criação dos filhos. Quanto ao primeiro aspecto, a proporção de indivíduos que não respondeu a essa questão foi muito elevada. Indicamos aqui possíveis razões para isso: porque não necessariamente uma única pessoa cuida, ou, ainda, porque a pergunta pode ter sido associada à idéia de existir alguém doente no momento da entrevista. ${ }^{6}$ De todo modo, o que podemos observar no item $\mathrm{C}$ da Tabela é que essa atividade continua sendo predominantemente feminina e, de acordo com as respostas, o envolvimento masculino permanece muito pequeno quando comparado ao envolvimento das mulheres.

Sobre o segundo aspecto, os dados da pesquisa confirmam o que foi dito anteriormente. Os filhos menores de dez anos, quando não estão na escola, recebem cuidados fundamentalmente da mãe - 57,6\% - e, em segundo lugar, dos avós $12,1 \%$-, o que deve corresponder, quase na sua totalidade, à figura da avó. Para as mulheres sem cônjuge, o suporte dos avós é ainda mais relevante. O cuidado público é residual - apenas 14,4\% dos entrevistados com filhos até 2 anos responderam positivamente à pergunta se os filhos freqüentam a creche, e só metade freqüenta creche do governo.

A divisão de trabalho doméstico entre casais, visando ao cuidado dos filhos, sugere poucas mudanças nos padrões tradicionais e confirma o que vem sendo encontrado em outros estudos. Em praticamente todas as atividades, $70 \%$ ou mais de mulheres respondem que são elas próprias que fazem as atividades listadas, ao passo que imputam ao cônjuge uma participação inexpressiva. A única exceção é em relação à atividade de brincar com as crianças, em que a participação masculina se eleva um pouco conforme pode ser visto na Tabela 8. Por fim, cabe registrar que também nos finais de semana, as mulheres, bem mais que os homens, tinham as suas atividades de lazer associadas às crianças e/ou visita a parentes, ou ainda usavam seu tempo livre para cuidar da casa. ${ }^{7}$

Certo padrão de respostas e aspectos curiosos e, ao mesmo tempo, reveladores, emergem desses dados, o que nos faz pensar acerca das formas como homens e mulheres experimentam e vivenciam essas atividades e a coerência com suas opiniões. Primeiro, quando comparamos as respostas de acordo com o sexo, notamos que, sistematicamente, o percentual de homens que respondem ser sempre eles que realizam as tarefas é mais elevado do que o de mulheres que atribuem ao cônjuge a responsabilidade pelas mesmas. Há, também, um padrão nas respostas sobre a divisão igualitária: o percentual de homens que responde dividir igualmente é sistematicamente maior do que o percentual de mulheres. Por fim, verificamos que isso ocorre quando de trata de atribuir à empregada doméstica a responsabilidade para com as atividades: sistematicamente os homens atribuem mais tarefas às empregadas do que as mulheres o fazem. Esse padrão aponta para uma importante distinção entre as percepções femininas e masculinas e será mais bem visualizado quando tratarmos do sentimento de justiça ou injustiça em relação ao trabalho doméstico, mas revelam, desde já, que não há sintonia entre o que os homens acham que fazem e o que acham que suas mulheres fazem e vice-versa.

\section{Relações entre valores e atitudes}

Após apresentar alguns dados descritivos, nosso objetivo nesse momento é compreender em que medida as percepções sobre o papel da 
mulher na vida pública e na vida privada têm impacto sobre a divisão das tarefas domésticas. Para tanto, recorremos a um modelo estatístico de regressões multivariadas. De antemão sabemos que esse impacto tem sido muito pequeno. Algumas das pesquisas mencionadas anteriormente, baseadas em séries temporais e em aferições mais diretas do uso tempo doméstico, têm demonstrado que em uma década o aumento do número de horas dedicadas ao trabalho doméstico pelos homens se alterou pouco, em torno de alguns minutos (Hirata, 2002). Essa constatação reforça a perspectiva discutida acima de que a divisão sexual do trabalho doméstico está fortemente enraizada na cultura, além de ser influenciada por outros fatores estruturais e econômicos. Com base nessas considerações e compreendendo que esse tipo de análise ajuda a visualizar melhor as distintas dimensões que a pesquisa permite captar, consideramos como uma hipótese subliminar que valores mais conservadores tendem a produzir percepções de gênero mais conservadoras, a quais, conseqüentemente, se refletem numa divisão do trabalho doméstico mais desigual. Nesse sentido, buscamos entender em que medida alguns valores mais gerais, que transcendem as relações de gênero e não estão relacionados apenas com as mulheres, têm implicações sobre a maneira de os indivíduos perceberem as relações de gênero e as práticas familiares. As variáveis utilizadas na construção de cada índice estão listadas no Anexo 3.

Em primeiro lugar, as correlações bivariadas ${ }^{8}$ entre os três índices criados para traduzir valores morais, percepções e práticas mostraram que existe uma associação positiva entre valores morais e percepções sobre o lugar da mulher na dinâmica entre o trabalho pago e a família, tanto para homens como para mulheres (ver Quadro 1, Anexo 2). Isso significa que quanto mais modernos são os "valores morais" mais igualitárias são as percepções sobre gênero, trabalho e família. No entanto, a correlação entre valores modernos e práticas igualitárias só é significativa no caso dos homens. Uma hipótese que pode ser levantada a partir desse resultado é que as mulheres, independentemente de seus valores e de suas percepções de gênero, fazem uma avaliação homogênea sobre a divisão do trabalho doméstico, ou seja, elas percebem igualmente a desigualdade dessa distribuição de tarefas. As práticas domésticas podem ser medidas mediante um indicador, denominado "prática", construído com base em um conjunto de variáveis que discriminam as atividades que os indivíduos realizam em casa e sua freqüência, já apresentados na primeira parte deste artigo.

É importante observar a diferença por gênero da média de horas semanais gastas em trabalhos domésticos, de acordo com as respostas dos inquiridos: 17,33 horas para homens e 37,37 horas para mulheres. Como é de se esperar, o inverso também ocorre, isto é, quando reportam à média dos cônjuges, essa relação se inverte: homens dizem que suas esposas gastam 35,59 horas, e mulheres, que seus maridos gastam 16,00 horas. Já as médias registradas para o índice "prática" repetem o padrão observado nas variáveis de tempo, pois médias maiores indicam uma percepção de distribuição das tarefas domésticas mais igualitárias. Os homens registram médias de 30,57 horas, ao passo que as mulheres, de 24,27 horas. Ou seja, os homens têm a perspectiva de que as tarefas são mais bem distribuídas, enquanto as mulheres acreditam que a distribuição seja mais assimétrica e desfavorável.

Diante do que foi discutido até então e com base nos dados, retomamos a hipótese de que diferenças nas práticas domésticas estariam vinculadas a percepções mais ou menos tradicionais sobre o lugar da mulher no mundo do trabalho e também na esfera privada. Por sua vez, e sem desconsiderar as observações anteriores, assumimos que a variação nas percepções poderia ser explicada pelos valores morais; assim, valores morais mais liberais e modernos levariam a percepções mais igualitárias, e estas à prática de uma melhor distribuição das tarefas domésticas. Variáveis sociodemográficas explicariam, por seu turno, os valores morais. Essas hipóteses permitem estruturar um modelo causal que se aproxima das dimensões analisadas por Norris e Inglehart (2003). Embora tal modelo esteja longe de esgotar a complexa multicausalidade existente na construção social do gênero e em suas práticas, ele permite operar com as distintas dimensões das variáveis incluídas no survey, indo além de sua simples descrição e tentando compreender as diversas 
correlações que se estabelecem entre essas dimensões. O que melhor se ajusta a esse tipo de construção de hipótese é o modelo de análise de trajetórias (path analysis). Entre as variáveis sociodemográficas foram incluídas: sexo; idade; escolaridade; zona residencial urbana/rural; freqüência a culto religioso e condição de ocupação (trabalha ou não trabalha). As variáveis nominais foram transformadas em dicotômicas, com valores 0 (zero) e 1 (um). No caso de gênero, o valor 1 (um) foi atribuído às mulheres; em zona residencial o valor 1 (um) corresponde à urbana; nas variáveis de trabalho, o valor 1 (um) foi atribuído aos que trabalham.

A primeira regressão tem como variável dependente a "moral" e como variáveis independentes: sexo, zona residencial, freqüência religiosa, idade, anos de estudo e condição de ocupação. Apesar do valor de $\mathrm{R}$ quadrado ser baixo, $6,4 \%$, o modelo é relevante na medida em que os resultados dos coeficientes beta-padronizados ${ }^{9}$ apontaram que zona residencial, sexo, freqüência religiosa e escolaridade têm relação significativa com valores morais no sentido de pessoas que vivem em áreas urbanas, mais educadas, do sexo feminino e com menor participação religiosa tendem a ter posições mais modernas no que diz respeito aos valores morais. O fato de estar inserido ou não no mercado de trabalho não tem influência sobre as opiniões sobre questões morais, bem como a idade dos respondentes. A variável de maior impacto é a escolaridade, seguida por sexo, freqüência religiosa e zona residencial. Condizente com outras pesquisas que vêm sugerindo certo conservadorismo dos jovens no que diz respeito a valores morais, constatamos também que ser jovem ou idoso não conta significativamente para os valores morais que os indivíduos assumem.

Num segundo momento, a hipótese testada foi a relação das variáveis sociodemográficas e do índice que mensura os valores morais sobre o índice que reporta percepções sobre gênero, trabalho e família - nomeado "percepções". Nesse índice não estão incluídos apenas itens de percepção, mas também aqueles referentes à opinião. Nesse caso, o valor de R quadrado é $16 \%$, o que pode ser considerado bom em se tratando de análises sociológicas. Os "valores morais" representam a maior influência sobre as percepções - quanto mais igualitários são eles, mais igualitárias são as percepções. Sexo e escolaridade também demonstram relação significativa com as percepções, na mesma direção que apresentaram quando a variável dependente era "valores morais" - ou seja, mulheres e pessoas mais escolarizadas tem percepções mais igualitárias. A idade registrou correlação negativa, isto é, quando cresce o valor da variável idade, diminui o da variável percepção. Neste caso das percepções de gênero, a idade é significativa: pessoas mais jovens registram índices mais modernos. O fato de ser mulher, como era de se esperar, não só tem mais relevância no caso das percepções do que no de valores morais, mas também apresenta, como variável independente, o mais elevado grau de significância. Já a religiosidade e a zona residencial parecem não ter influência direta sobre as percepções, mas influencia somente os valores morais.

Por último, é apresentado o modelo que inclui como variável dependente o índice denominado "prática", que se refere à divisão das tarefas domésticas. Quanto maior o índice, melhor é a percepção ou o julgamento do respondente sobre a distribuição das tarefas, traduzindo, portanto, a sensação de serem as práticas mais igualitárias e as tarefas domésticas mais bem divididas entre os cônjuges.

Existe relação entre percepção e prática, o que indica que opiniões igualitárias se traduzem em atitudes menos conservadoras, sempre considerando que se está falando da forma como a distribuição do trabalho doméstico é percebida e sentida pelos respondentes. Contudo, nesse caso, somente a variável sociodemográfica tem relação significativa com a distribuição do trabalho doméstico, qual seja, o sexo; e o sentido dessa correlação é negativo. Isto é, a opinião sobre distribuição das práticas é diretamente associada ao sexo: ser mulher implica o reconhecimento de que são elas que fazem a maior parte do trabalho doméstico. Deve-se salientar que esta variável também é pautada em percepção e opinião, já que os respondentes opinam sobre o quanto fazem na divisão do trabalho doméstico.

É revelador o fato de que estar ou não inserido em um trabalho pago tem efeito nulo sobre percepções e práticas. Mas esse fenômeno pode ser explicado pela alta taxa de inserção dos 
homens na força de trabalho, que representa praticamente a totalidade dos respondentes do sexo masculino, influenciando assim o índice. Por essa razão, a análise não estaria completa sem que os modelos fossem aplicados somente às mulheres, mesmo porque o interesse desta pesquisa não é estudar apenas as diferenças de percepção entre homens e mulheres, mas também as diferenças de percepção entre mulheres com perfis sociodemográficos distintos. Nesse sentido, é necessário verificar se o fato de estar ou não inserida no mercado de trabalho tem impacto sobre as percepções, assim como os diferenciais em educação, geração, área de residência, entre outros. Ou seja, a pergunta não diz respeito somente ao que explica as diferenças de opinião e percepção da população como um todo, mas, em especial, ao que explica as diferenças entre a população feminina, isto é, o que faz com que as mulheres se diferenciem nessa dimensão das práticas, valores e percepções sobre seu lugar nas esferas pública e privada.

Novamente, é baixo o R quadrado $(6,5 \%)$ da regressão que inclui valores morais como variável dependente e como variáveis independentes sexo, zona residencial, freqüência religiosa, idade, anos de estudo e condição de ocupação. Ainda assim, a análise dos beta-padronizados apontou que zona residencial, freqüência religiosa e escolaridade têm relação significativa com valores morais no sentido de as mulheres que vivem em áreas urbanas, mais educadas e com menor participação religiosa tendem a ter posições mais modernas no que diz respeito a valores morais. O fato de estar inserido ou não no mercado de trabalho continua não tendo influência sobre as opiniões sobre questões morais, como havia ocorrido para a população como um todo. Entre as mulheres, a variável de maior impacto é a escolaridade, seguida de zona residencial e freqüência religiosa. Nesse primeiro modelo, o resultado para os dados das mulheres foi similar ao observado para a população em geral. Entretanto, quando a regressão tem como variável dependente o índice de percepção surgem algumas diferenças. $\mathrm{O} R$ quadrado é de $16 \%$, e a variável "condição na ocupação" mostra ter poder explicativo: mulheres que estão inseridas no mercado de trabalho têm percepçôes mais igualitárias e modernas. Ainda assim, a variável "valores morais" continua sendo a que tem maior peso no modelo, sendo que idade e escolaridade tem impacto menor do que inserção na força de trabalho, nesta ordem.

Aqui é relevante destacar que nessa última regressão nenhuma variável tem relação significativa com a opinião sobre a igualdade ou a desigualdade na divisão das tarefas domésticas. Essa opinião depende única e exclusivamente de um fator: o sexo do respondente. Ou seja, esse resultado indica que mulheres de diferentes níveis educacionais, áreas de residência, gerações, trabalhando fora ou não, com distintas percepções e valores morais sentem compartilhar uma experiência comum: a assimetria das tarefas domésticas. Em trabalho mais detalhado sobre os resultados desta pesquisa (Araújo e Scalon, 2004), mostramos que, em termos percentuais, havia algumas diferenças entre os índices de envolvimento das mulheres com o trabalho doméstico de acordo com a condição de atividade. E isto tem certa lógica. Trabalhar fora tende a implicar em determinado número de horas disponíveis para essas atividades. Porém, o que esta parte da análise mostra é que tal fator não se constitui em condição significativa e suficiente para mudar substancialmente as posições de ambos os sexos em relação ao trabalho doméstico. Por sua vez, como o índice "percepção" mostrouse significativo para o total da população, podemos concluir que esse efeito se deve à opinião dos homens; ou seja, homens com percepções e opiniões mais igualitárias tendem a perceber suas práticas domésticas também como mais igualitárias.

É ainda relevante analisar a relação entre o número de horas semanais que homens e mulheres responderam dedicar ao trabalho doméstico e as percepções dos entrevistados sobre fazer a parte justa nas tarefas domésticas, conforme mostra o Quadro 2 (Anexo 2).

Nesse ponto, homens e mulheres estão sendo analisados separadamente. Assim, a análise de variância mostra que existe uma associação significativa entre as horas de fato dedicadas ao trabalho doméstico e o sentido de justiça da participação neste. Isto é, homens que reportam fazer mais do que o justo, de fato, dedicam mais horas do que aqueles que dizem fazer o justo, e, estes, mais do que os que reconhecem fazer menos que o justo. O que chama atenção é a discrepância nas médias de horas trabalhadas entre os sexos - as 
mulheres dedicam às tarefas domésticas, em média, mais do que o dobro de horas que os homens - isto ocorre entre todos os três grupos, a saber, que fazem mais do que o justo, o justo e menos do que o justo.

É interessante observar que o número de mulheres que reportam fazer mais ou o justo é bem mais elevado do que o de homens. De fato, o número de mulheres que diz fazer "menos do que o justo" é bastante reduzido - quinze casos-, da mesma forma, o número de homens que diz fazer "mais do que o justo" é pequeno - 31 casos. Quando considerado o número efetivo de horas dedicadas ao trabalho doméstico, verifica-se que os homens que acreditam fazer "mais do que o justo" trabalham, em média, menos horas do que as mulheres que reconhecem fazer "menos do que o justo", apesar de devermos ter cuidado ao analisar esses dados, uma vez que o número de casos é pequeno. De qualquer maneira, as médias de horas já indicavam a discrepância entre a dedicação das mulheres e dos homens às atividades domésticas. Mas os resultados também apontam certa discrepância entre o que dizem fazer efetivamente e o sentido que atribuem a essa responsabilidade. Isto porque, embora reconheçam trabalhar muito mais, não predomina entre as mulheres um sentido de injustiça, o que revela ainda uma forte naturalização sobre suas responsabilidades domésticas. Quanto aos homens, embora reconheçam fazer muito menos e a proporção dos que reportam fazer "menos que o justo" seja bem maior do que entre as mulheres, o que indica algum olhar crítico, o fato é que o sentido que predomina entre eles é o de justiça, o que também parece revelar a permanência de um ideal de provedor no qual as atividades domésticas entram como ajuda e auxílio e não como dado constitutivo da reprodução de sua vida.

Por fim, procuramos analisar também as respostas sobre a freqüência com que os respondentes dizem discordar de seus cônjuges sobre a divisão do trabalho doméstico. ${ }^{10}$ As respostas reforçam a suspeita da discrepância acima mencionada, dada a baixa freqüência de conflitos registrados: $78,8 \%$ das mulheres e $81,2 \%$ dos homens responderam que nunca ou raramente têm conflitos sobre a divisão das atividades domésticas. ${ }^{11}$ É interessante observar que mesmo entre as mulheres que se identificaram como ativas $77,8 \%$ dizem que quase nunca ou raramente têm conflitos com o cônjuge. Embora esse dado aponte para um fraco grau de tensão, os dados relacionados com número de horas, distribuição de atividades e avaliação de justiça permitem considerar a possibilidade de que essa tensão, motivada pelas respostas anteriores sobre percepções e o crescente envolvimento feminino com o trabalho pago, seja mais elevada, mesmo quando não se traduz em conflitos explícitos.

\section{Conclusão}

Como melhorar a relação entre vida familiar e trabalho? Essa foi uma das perguntas feitas aos inquiridos e que comportava resposta por ordem de preferência em relação a um conjunto de estratégias. Homens e mulheres responderam, como primeira opção, poder trabalhar mais para ganhar mais dinheiro. A escolha parece apontar para uma característica mais pragmática e monetarizada que a vida social vem adquirindo nos últimos tempos e para o modelo fluido, de necessidade de satisfação imediata como elemento associado à satisfação em geral, nos moldes sugeridos por Bauman (1994). No caso do Brasil, há ainda que se considerar a precariedade das condições de vida que marca o cotidiano de boa parte da população. Mas o interessante é que as primeiras opções feitas pelas mulheres, que se assemelham, no tipo de atividade, às opções dos homens, estão relacionadas ao trabalho e, em seguida, ao lazer. Com efeito, nas diferentes situações as respostas, particularmente das mulheres, apontaram para a atividade de trabalho pago como um dado constitutivo e também valorizado como construção identitária da vida social.

A análise de multivariância, com base no modelo de trajetória, indica que determinados fatores socioeconômicos contribuem para valores morais e percepções mais igualitárias. A escolaridade importa na formação de valores morais mais modernos. A análise sobre as percepções mostrou que, em geral, as mulheres tendem a ter posições ligeiramente mais igualitárias do que os homens quanto a) ao papel do trabalho na realização profissional; b) à capacidade de exercer maternidade 
fora do casamento, c) ao próprio papel do casamento na construção da felicidade; e d) à sexualidade. Mas nem todas as mulheres pensam do mesmo modo. Assim como para a população geral, ser de zona urbana, ter fraca religiosidade e elevada escolaridade contam em se tratando de valores mais modernos. O trabalho pago influencia na construção dos valores e das percepções. Se em relação aos homens a condição de atividade não altera muito seus valores, entre as mulheres percebemos que, além da escolaridade, a condição de ocupação - estar ou não inserida no mercado de trabalho - revela a importância da atividade de trabalho pago como elemento de redefinição de valores. Em geral, mulheres que trabalham têm percepções mais críticas acerca das práticas tradicionais e apresentam opiniões mais favoráveis à igualdade de gênero. De outra parte, em relação ao que definimos como "práticas", os resultados corroboram pesquisas feitas em outros países que apontam para uma fraca relação entre percepções e práticas e entre condição de atividade e práticas. As opiniões tendencialmente mais igualitárias não se traduzem em práticas mais compartilhadas por parte dos homens. É certo que há algum condicionamento, na medida em que o tempo dedicado ao trabalho doméstico aumenta um pouco quando ambos trabalham, mas não de forma significativa. A dimensão do gênero surge como extremamente relevante, e o sexo determina os limites das práticas. Em outras palavras, a divisão sexual do trabalho doméstico e as atribuições de homens e mulheres relacionadas com o trabalho de reprodução cotidiana da vida social permanecem como um dos aspectos menos permeáveis às mudanças que marcam a sociedade contemporânea.

\section{Notas}

1 A amostra nacional, domiciliar e representativa da população brasileira foi composta de 2 mil indivíduos, definida por cotas a partir de sua condição de sexo, escolaridade, idade e região - urbana e rural. A coleta dos dados foi feita pelo Instituto Sensus de Pesquisa, entre os meses de novembro e dezembro de 2003 com base num questionário padrão internacional construído pelo ISSP, acrescido de questões locais. Além das autoras, que coordenaram a pesquisa, participaram também outros oito pesquisadores de diferentes instituições acadêmicas. Os resultados mais gerais, bem como as contribuições desses pesquisadores, encontram-se em Gênero, família e trabalho no Brasil, 2005, editado pela Fundação Getúlio Vargas. No Relatório de Pesquisa (2004) encontra-se o conjunto dos resultados analisados de forma mais detalhada. Este artigo consiste numa síntese de alguns dos principais dados e conclusões empíricas obtidos pela pesquisa.

2 Aqui, as atitudes remetem às questões que reportam à realização de tarefas domésticas, isto é, o que os entrevistados dizem que fazem quando inquiridos. Para efeito de análise, definimos essas atividades como "práticas".

3 Tomando como um dado o já exaustivo debate sobre relações de gênero e de sexo na literatura da área, considera-se que este conceito dispensa maiores digressões.

4 De acordo com estudos históricos, no Brasil, "ao longo dos oitocentos, até a década de 1870, as solicitações de separação foram feitas, sobretudo, pelas esposas" (Brugger, 2005, p. 69), o que sugere que este não é um dado decorrente apenas desse processo de modernização.

5 Pela natureza das questões, esse bloco será objeto de breves comentários, tendo sido mais bem analisado em Araújo e Scalon (2004) e em outro artigo específico a ser ainda publicado.

6 Nesse sentido, consideramos que a pergunta poderia ter sido mais bem elaborada, embora no préteste esse aspecto não tivesse sido relevante.

7 A esse respeito, ver os dados do relatório (Araújo e Scalon, 2004).

8 Correlações bivariadas são aquelas que inserem a relação entre duas variáveis. Quando o número de variáveis ultrapassa dois, a análise passa a ser denominada de multivariada.

9 São os coeficientes resultantes da análise de regressão que expressam o peso relativo de cada variável independente sobre a variável dependente.

10 As alternativas variavam desde "várias vezes por semana" até "nunca".

11 A pergunta não incluía as atividades com os filhos.

\section{Bibliografia}

ABOIM, Sofia \& WALL, Karin. (2002), "Tipos de família em Portugal: interações, valores e contextos". Análise Social - Revista do Instituto de Ciências Sociais da Universidade de Lisboa, 37 (163): 475-506. 
ARAÚJO, Clara \& SCALON, Celi. (2004), "Práticas e percepções de homens e mulheres sobre a conciliação entre família e trabalho". Relatório de pesquisa, Rio de Janeiro, Faperj, nov.

(orgs.). (2005), Gênero, família e trabalho no Brasil. Rio de Janeiro, Fundação Getulio Vargas Editora.

ARRIAGADA, I. (2004), "Estructuras familiares, trabajo y bienestar en América Latina", in , Cambio de las Familias, Santiago, Cepal/UNFPA.

BAUMAN, Zigmunt. (1994), Amor líquido: sobre a fragilidade dos laços humanos. Rio de Janeiro, Zahar.

BATHYÁNY, Karina. (2000), "Estado, família, políticas sociales: quien se hace cargo de los cuidados y las responsabilidades familiares?". Revista de Ciencias Sociales, 18: 83-95, set.

BERQUÓ, Elza. (2002), "Perfil demográfico das chefias femininas no Brasil", in C. Bruschini e S. Umbehaum (orgs.), Gênero, democracia e sociedade brasileira, São Paulo, Fundação Carlos Chagas/Editora 34.

BOZON, M. (2004), Sociologia da sexualidade. Rio de Janeiro, Fundação Getulio Vargas Editora.

(2003), "Sexualidade e conjugalidade: a redefinição das relações de gênero na França contemporânea". Cadernos PAGU, 20: 131-156.

BRUGGER, Silvia M. (2005), "Divórcio e casamento nos oitocentos". Revista Nossa História, 2 (22): 68-71.

BRUSCHINI, Cristina. (1990), Mulher, casa e familia. São Paulo, FCC/Vértice.

CASTELLS, Manuel. (2000), O poder da identidade. Rio de Janeiro, Paz e Terra.

DEDDECA, Cláudio. (2004), "Tempo, trabalho e gênero". Campinas, IE/Unicamp (mimeo.).

DURAN, María-Angels. (2000), "Uso del tiempo y trabajo no remunerado". Revista de Ciências Sociais, 18: 56-69.

ESPING-ANDERSON, G. (1990), The three worlds of welfare capitalism. Princeton, NJ, Princeton University Press.
FRASER, N. (1999), "A luta pelas necessidades: esboço de uma teoria crítica socialistafeminista da cultura política do capitalismo tardio". Debate Feminista, n. especial, São Paulo, Metis Productos Culturales.

CROMPTON, R. (1999), Restructuring gender relations and employment: the decline of the male breadwiner. Oxford, UK, Oxford University Press.

GIDDENS, Anthony. (1991), As transformaçôes da intimidade. São Paulo, Editora da Unesp.

GORNICK, J. \& MEYERS, M. (2004), "Welfare regimes in relations to paid work and care", in J. Giele e E. Holst (eds.), Changing life patterns in Western industrial societies, Netherlands, Elsevier Science Press.

HIRATA, Helena. (2002), "Reorganização da produção e transformações do trabalho: uma nova divisão sexual?", in $\mathrm{C}$. Bruschini e $\mathrm{S}$. G. Unbehaum (orgs.), Gênero, democracia e sociedade, São Paulo, Fundação Carlos Chagas/Editora 34.

HIRATA, Helena \& HUMPRHEY, J. (1986), "Division sexuelle du travail dans l'industrie bresiliéne", in N. Aubert, E. Enriquez e V. de Gaulejac (orgs.), Le sex du pouvoir, Paris, EPI.

JELLIN, Elizabeth. (1995), Família y gênero: notas para el debate. Estudos Feministas, 3, (2): 394-413.

NORRIS, P. \& INGLEHART, R. (2003), Rising tide: gender equality \& cultural changes around the world. Nova York, Cambridge University Press.

TORRES, Anália. (2001), "Casamento e gênero: mudanças nas famílias contemporâneas a partir do caso português". Revista Interseções, 3 (2): 53-70, jul.-dez.

. (2004), Vida conjugal e trabalbo: uma perspectiva sociológica. Lisboa, Celta.

TORRES, Anália et al. (2002), Homens e mulheres entre família e trabalho. Lisboa, Cies/ISCTE.

VAITSMAN, Jeni. (1994), Flexíveis e plurais: identidade, casamento e família em circunstâncias pós-modernas. Rio de Janeiro, Rocco. 


\section{Anexos}

Tabela 1

Opinião sobre Trabalho, Maternidade e Vida Familiar

\begin{tabular}{|c|c|c|c|c|c|c|c|c|}
\hline SEXO & RESPOSTA & A & B & $\mathrm{C}$ & $\mathrm{D}$ & $\mathrm{E}$ & $\mathrm{F}$ & G \\
\hline \multirow{7}{*}{ MASCULINO } & Concorda totalmente & 55,7 & 71,2 & 53,7 & 58,2 & 57,2 & 77,7 & 47,1 \\
\hline & Concorda em parte & 18,5 & 13,5 & 12,8 & 13,2 & 14,5 & 10,8 & 14,2 \\
\hline & Não concorda nem discorda & 4,3 & 3,4 & 8,1 & 6,3 & 5,4 & 1,7 & 3,6 \\
\hline & Discorda em parte & 6,2 & 4,0 & 8,4 & 8,0 & 7,2 & 2,9 & 10,9 \\
\hline & Discorda totalmente & 15,4 & 7,9 & 17,0 & 14,2 & 15,7 & 6,9 & 24,2 \\
\hline & Total & 100,0 & 100,0 & 100,0 & 100,0 & 100,0 & 100,0 & 100,0 \\
\hline & $\mathbf{N}$ & 957 & 949 & 900 & 934 & 949 & 956 & 955 \\
\hline \multirow{7}{*}{ FEMININO } & Concorda totalmente & 59,6 & 82,0 & 46,9 & 52,0 & 58,7 & 79,8 & 49,1 \\
\hline & Concorda em parte & 20,1 & 10,4 & 13,9 & 15,0 & 15,7 & 10,1 & 15,2 \\
\hline & Não Concorda nem discorda & 2,6 & 1,8 & 6,4 & 6,1 & 4,0 & 1,3 & 3,2 \\
\hline & Discorda em parte & 6,7 & 2,8 & 10,0 & 8,5 & 7,7 & 2,2 & 9,3 \\
\hline & Discorda totalmente & 11,0 & 3,0 & 22,8 & 18,4 & 14,0 & 6,6 & 23,1 \\
\hline & Total & 100,0 & 100,0 & 100,0 & 100,0 & 100,0 & 100,0 & 100,0 \\
\hline & $\mathbf{N}$ & 995 & 995 & 993 & 996 & 987 & 995 & 997 \\
\hline Total Geral & & 1.952 & 1.944 & 1.893 & 1.930 & 1.936 & 1.951 & 1.952 \\
\hline
\end{tabular}

Questões:

A - Mulher casada que trabalha fora melhora o nível de vida da família?

B - Trabalhar fora é o melhor jeito de a mulher se tornar independente?

C - Ser dona de casa é tão gratificante quanto trabalhar fora?

D - Trabalhar é bom, mas o que a maioria das mulheres quer mesmo é ter lar e filhos?

E - No final, a vida familiar fica prejudicada se a mulher trabalha em tempo integral?

$\mathrm{F}$ - As crianças sofrem mais se a mãe trabalha fora?

G - Uma mãe que trabalha fora pode estabelecer uma relação tão carinhosa com seus filhos quanto uma mãe que não trabalha? 
Tabela 2

Opinião se a Mulher Deve Trabalhar fora de Casa

\begin{tabular}{|c|c|c|c|c|c|}
\hline SEXO & RESPOSTA & A & $\mathrm{B}$ & $\mathrm{C}$ & $\mathrm{D}$ \\
\hline \multirow{5}{*}{ MasculinO } & Período integral & 47,5 & 15,5 & 29,2 & 51,7 \\
\hline & Meio expediente & 31,4 & 37,0 & 42,1 & 23,8 \\
\hline & Não trabalhar fora & 21,1 & 47,5 & 28,8 & 24,6 \\
\hline & Total & 100,0 & 100,0 & 100,0 & 100,0 \\
\hline & $\mathrm{N}$ & 928 & 937 & 939 & 908 \\
\hline \multirow{5}{*}{ FEMININO } & Período integral & 57,3 & 17,9 & 34,7 & 63,1 \\
\hline & Meio expediente & 33,0 & 48,5 & 46,7 & 22,4 \\
\hline & Não trabalhar fora & 9,7 & 33,5 & 18,6 & 14,5 \\
\hline & Total & 100,0 & 100,0 & 100,0 & 100,0 \\
\hline & $\mathrm{N}$ & 965 & 975 & 969 & 941 \\
\hline Total Geral & & 1.893 & 1.912 & 1.908 & 1.849 \\
\hline
\end{tabular}

Questões - A mulher deve trabalhar fora:

A - depois de casar e antes de ter filhos?

$\mathrm{B}$ - quando tem filho pequeno?

C - quando o filho caçula entra na escola?

D - quando os filhos saem de casa?

Tabela 3

Opinião sobre Participação Masculina na Provisão e na Divisão de Tarefas Domésticas

\begin{tabular}{|c|l|r|r|r|r|r|}
\hline SEXO & RESPOSTA & \multicolumn{1}{|c|}{ A } & \multicolumn{1}{c|}{ B } & \multicolumn{1}{c|}{ C } & \multicolumn{1}{c|}{ D } & \multicolumn{1}{c|}{ E } \\
\hline \multirow{5}{*}{ MASCULINO } & Concorda totalmente & 84,9 & 40,5 & 49,7 & 62,6 & 50,6 \\
& Concorda em parte & 7,6 & 11,8 & 17,3 & 19,0 & 19,6 \\
& Não concorda nem discorda & 1,8 & 7,1 & 6,1 & 3,9 & 5,4 \\
& Discorda em parte & 1,3 & 8,5 & 6,8 & 4,1 & 6,2 \\
& Discorda totalmente & 4,4 & 32,0 & 20,1 & 10,3 & 18,2 \\
& Total & 100,0 & 100,0 & 100,0 & 100,0 & 100,0 \\
& N & 977 & 972 & 968 & 968 & 965 \\
\hline \multirow{5}{*}{ FEMININO } & Concorda totalmente & 85,6 & 35,0 & 65,1 & 72,5 & 63,8 \\
& Concorda em parte & 8,0 & 10,1 & 14,6 & 14,2 & 17,7 \\
& Não concorda nem discorda & 1,2 & 5,3 & 3,4 & 2,6 & 2,4 \\
& Discorda em parte & 1,2 & 10,5 & 5,4 & 3,7 & 5,7 \\
& Discorda totalmente & 4,0 & 39,2 & 11,5 & 6,9 & 10,3 \\
& Total & 100,0 & 100,0 & 100,0 & 100,0 & 100,0 \\
& N & 1.000 & 1.001 & 990 & 998 & 992 \\
\hline Total Geral & & $\mathbf{1 9 7 7}$ & $\mathbf{1 9 7 3}$ & $\mathbf{1 9 5 8}$ & $\mathbf{1 9 6 6}$ & $\mathbf{1 9 5 7}$ \\
\hline
\end{tabular}

Questões:

A - Homens e mulheres devem contribuir para renda familiar?

$\mathrm{B}$ - O homem deve ganhar dinheiro e a mulher deve cuidar da casa?

C - Homens devem assumir mais trabalhos domésticos?

$\mathrm{D}$ - Homens devem cuidar mais das crianças?

E - Homens e mulheres deveriam dividir igualmente as tarefas domésticas? 
Tabela 4

Posições sobre o Papel do Casamento na Conjugalidade em face das Afirmações

\begin{tabular}{|c|c|c|c|c|c|c|c|}
\hline SEXO & RESPOSTA & A & B & $\mathrm{C}$ & D & $\mathrm{E}$ & $\mathrm{F}$ \\
\hline \multirow{5}{*}{ MasculinO } & Concorda & 43,8 & 11,9 & 60,5 & 62,1 & 69,7 & 85,5 \\
\hline & Não concorda nem discorda & 14,9 & 2,4 & 5,0 & 5,7 & 4,2 & 1,8 \\
\hline & Discorda & 41,2 & 85,7 & 34,5 & 32,2 & 26,1 & 12,7 \\
\hline & Total & 100,0 & 100,0 & 100,0 & 100,0 & 100,0 & 100,0 \\
\hline & $\mathrm{N}$ & 970 & 1.002 & 995 & 998 & 997 & 993 \\
\hline \multirow{5}{*}{ FEMININO } & Concorda & 56,6 & 12,5 & 65,1 & 57,4 & 68,2 & 86,8 \\
\hline & Não concorda nem discorda & 10,6 & 1,7 & 4,5 & 5,2 & 3,3 & 2,0 \\
\hline & Discorda & 32,8 & 85,9 & 30,4 & 37,4 & 28,5 & 11,3 \\
\hline & Total & 100,0 & 100,0 & 100,0 & 100,0 & 100,0 & 100,0 \\
\hline & $\mathrm{N}$ & 956 & 969 & 968 & 970 & 964 & 967 \\
\hline Total Geral & & 1.962 & 1.971 & 1.966 & 1.965 & 1.961 & 1.960 \\
\hline
\end{tabular}

Questões:

A - Casados são mais felizes do que solteiros?

B - É melhor um casamento ruim do que não estar casado?

C - Quem quer ter filhos deve casar?

D - Pai/mãe sozinhos podem criar um filho tão bem quanto um casal?

E - Está certo um casal viver junto sem querer casar?

F - O divórcio é a melhor solução para um casal que não consegue resolver seus problemas de relacionamento? 
Tabela 5

Opiniões sobre Moralidade Sexual - Ativos

\begin{tabular}{|c|c|c|c|c|c|c|c|}
\hline SEXO & RESPOSTA & A & B & $\mathrm{C}$ & $\mathrm{D}$ & $\mathrm{E}$ & $\mathrm{F}$ \\
\hline \multirow{8}{*}{ MulHer } & Concorda totalmente & 19,5 & 15,6 & 25,8 & 79,6 & 14,1 & 41,9 \\
\hline & Concorda em parte & 6,1 & 8,3 & 7,2 & 7,8 & 7,1 & 16,9 \\
\hline & Não concorda nem discorda & 1,9 & 3,9 & 1,9 & 2,2 & 2,4 & 5,9 \\
\hline & Discorda em parte & 8,3 & 8,3 & 7,4 & 2,2 & 10,8 & 7,6 \\
\hline & Discorda totalmente & 62,2 & 58,4 & 56,4 & 6,5 & 63,5 & 26,0 \\
\hline & NS/NR & 2,0 & 5,4 & 1,3 & 1,7 & 2,2 & 1,7 \\
\hline & Total & 100,0 & 100,0 & 100,0 & 100,0 & 100,0 & 100,0 \\
\hline & $\mathbf{N}$ & 539 & 539 & 539 & 539 & 539 & 539 \\
\hline \multirow{8}{*}{ HoMem } & Concorda totalmente & 26,8 & 20,7 & 28,9 & 68,4 & 22,1 & 44,4 \\
\hline & Concorda em parte & 8,1 & 9,8 & 7,4 & 9,7 & 9,4 & 13,7 \\
\hline & Não concorda nem discorda & 2,3 & 3,9 & 2,5 & 3,1 & 6,4 & 7,4 \\
\hline & Discorda em parte & 8,1 & 8,4 & 6,9 & 4,5 & 10,4 & 7,9 \\
\hline & Discorda totalmente & 52,8 & 53,6 & 52,9 & 13,1 & 49,4 & 26,1 \\
\hline & NS/NR & 1,8 & 3,6 & 1,4 & 1,3 & 2,3 & 0,5 \\
\hline & Total & 100 & 100 & 100 & 100 & 100 & 100 \\
\hline & $\mathbf{N}$ & 786 & 786 & 786 & 786 & 786 & 786 \\
\hline \multicolumn{2}{|c|}{ Total Geral (N) } & 1.325 & 1.325 & 1.325 & 1.325 & 1.325 & 1.325 \\
\hline
\end{tabular}

Questões:

A - O homem deve punir a mulher em caso de infidelidade?

B - Ameaça é eficaz em caso de adultério?

C - A mulher deve punir o marido em caso de adultério?

D - Preservativo deve ser usado por todos os casais?

E - A mulher casada deve fazer sexo com o marido quando ele quiser?

F - Prevenção da gravidez deve ser responsabilidade da mulher? 
Tabela 6

Opiniões a respeito do Aborto

\begin{tabular}{|c|c|c|c|c|c|c|}
\hline SEXO & RESPOSTA & A & B & $\mathrm{C}$ & $\mathrm{D}$ & $\mathrm{E}$ \\
\hline \multirow{8}{*}{ MulHer } & Concorda totalmente & 71,4 & 59,8 & 57,9 & 16,2 & 39,5 \\
\hline & Concorda em parte & 9,7 & 8,9 & 6,7 & 10,6 & 11,5 \\
\hline & Não concorda nem discorda & 3,0 & 3,2 & 4,1 & 4,6 & 5,2 \\
\hline & Discorda em parte & 2,2 & 4,6 & 4,9 & 9,8 & 8,6 \\
\hline & Discorda totalmente & 10 & 17,2 & 22 & 55,4 & 30,7 \\
\hline & $\mathrm{NS} / \mathrm{NR}$ & 3,7 & 6,2 & 4,3 & 3,2 & 4,5 \\
\hline & Total & 100 & 100 & 100 & 100 & 100 \\
\hline & $\mathbf{N}$ & 1.016 & 1.016 & 1.016 & 1.016 & 1.016 \\
\hline \multirow{8}{*}{ HOMEM } & Concorda totalmente & 69,9 & 61,8 & 58,5 & 19,6 & 44 \\
\hline & Concorda em parte & 11,3 & 8,2 & 6,5 & 8,3 & 12,7 \\
\hline & Não concorda nem discorda & 2,0 & 4,6 & 3,7 & 6,2 & 5,2 \\
\hline & Discorda em parte & 3,2 & 5,2 & 5,1 & 7,2 & 7,4 \\
\hline & Discorda totalmente & 10,1 & 16,2 & 21,5 & 55 & 26,8 \\
\hline & NS/NR & 3,6 & 4,1 & 4,7 & 3,7 & 3,9 \\
\hline & Total & 100 & 100 & 100 & 100 & 100 \\
\hline & $\mathbf{N}$ & 984 & 984 & 984 & 984 & 984 \\
\hline \multicolumn{2}{|c|}{ Total Geral (N) } & 2.000 & 2.000 & 2.000 & 2.000 & 2.000 \\
\hline
\end{tabular}

Questões:

A - Aborto deve ser garantido em caso de risco de saúde para a mãe?

B - Aborto deve ser garantido em caso de anomalia fetal?

C - Aborto deve ser garantido em caso de estupro?

D - Aborto é um direito da mulher?

E - Mulher que faz aborto deve ser presa. 
Tabela 7

Opinião sobre as Tarefas Domésticas

\begin{tabular}{|c|c|c|c|c|c|c|c|c|c|c|c|c|c|c|}
\hline \multirow{2}{*}{$\begin{array}{l}\text { DISTRIBUIÇÃO } \\
\text { DOS ENTREVISTADOS } \\
\text { POR TAREFAS } \\
\text { DOMÉSTICAS }\end{array}$} & \multicolumn{2}{|c|}{ A } & \multicolumn{2}{|c|}{ B } & \multicolumn{2}{|c|}{ C } & \multicolumn{2}{|c|}{$\mathrm{D}$} & \multicolumn{2}{|c|}{ E } & \multicolumn{2}{|c|}{$\mathrm{F}$} & \multicolumn{2}{|c|}{$\mathrm{G}$} \\
\hline & $\mathrm{H}$ & M & $\mathrm{H}$ & M & $\mathrm{H}$ & M & $\mathrm{H}$ & M & $\mathrm{H}$ & M & $\mathrm{H}$ & M & $\mathrm{H}$ & M \\
\hline Sempre eu & 2,3 & 73,9 & 53,8 & 12,4 & 6,2 & 47,9 & 17,1 & 39,7 & 3,7 & 64,3 & 3,9 & 69,9 & 5,6 & $\overline{59,8}$ \\
\hline Geralmente eu & 1,9 & 11,4 & 24,8 & 4,5 & 3,5 & 9,9 & 7,2 & 13,3 & 1,8 & 13,8 & 2,1 & 12,0 & 2,8 & $\overline{13,5}$ \\
\hline Igualmente & 6,9 & 3,7 & 5,3 & 8,3 & 39,3 & 29,7 & 34,3 & 26,4 & 14,8 & 8,5 & 13,8 & 8,5 & 18,9 & $\overline{10,3}$ \\
\hline $\begin{array}{l}\text { Geralmente } \\
\text { cônjuge }\end{array}$ & 38,1 & 0,7 & 5,3 & 36,4 & 18,9 & 2,5 & 18,8 & 8,7 & 33,7 & 1,0 & 32,7 & 1,4 & 30,3 & 2,4 \\
\hline Sempre cônjuge & 41,5 & 0,5 & 5,0 & 26,9 & 22,6 & 2,1 & 18,7 & 6,1 & 35,4 & 0,7 & 39,0 & 0,9 & 32,1 & 1,4 \\
\hline $\begin{array}{l}\text { Outra pessoa } \\
\text { da família }\end{array}$ & 4,0 & 6,0 & 3,6 & 8,6 & 7,9 & 6,9 & 2,6 & 4,9 & 5,6 & 7,5 & 4,8 & 5,1 & 5,6 & 9,8 \\
\hline Outros & 5,2 & 3,8 & 2,1 & 2,7 & 1,6 & 0,9 & 1,3 & 0,9 & 5,0 & 4,1 & 3,8 & 2,2 & 4,6 & 2,9 \\
\hline Total & 100,0 & 100,0 & 100,0 & 100,0 & 100,0 & 100,0 & 100,0 & 100,0 & 100,0 & 100,0 & 100,0 & 100,0 & 100,0 & 100,0 \\
\hline $\mathbf{N}$ & 569 & 587 & 433 & 434 & 561 & 579 & 568 & 587 & 567 & 585 & 566 & 585 & 567 & 584 \\
\hline
\end{tabular}

Questões - Em sua casa, quem:

A - lava e passa roupa?

$\mathrm{B}$ - faz pequenos consertos?

$\mathrm{C}$ - cuida dos familiares doentes?

D - compra comida?

E - limpa a casa?

$\mathrm{F}$ - cozinha?

G - lava os pratos?

$\mathrm{H}$ - vai ao banco/paga as contas?

Tabela 8

Respondentes que Trabalham mais de 40 Horas Semanais Segundo o Tempo Dedicado ao Trabalho Doméstico

\begin{tabular}{|c|c|c|c|}
\hline \multirow{2}{*}{$\begin{array}{l}\text { TEMPO DEDICADO AO TRABALHO } \\
\text { DOMÉSTICO EM HORAS SEMANAIS }\end{array}$} & \multicolumn{3}{|c|}{$\begin{array}{l}\text { RESPONDENTES QUE TRABALHAM } \\
\text { MAIS DE } 40 \text { HORAS POR SEMANA }\end{array}$} \\
\hline & Homem & Mulher & Total \\
\hline Nenhuma & 38,5 & 16,2 & 31,9 \\
\hline Até 10 horas & 38,9 & 19,8 & 33,2 \\
\hline De 11 até 20 horas & 13,0 & 21,6 & 15,5 \\
\hline De 21 até 30 horas & 3,8 & 25,2 & 10,2 \\
\hline 30 horas ou mais & 5,7 & 17,1 & 9,1 \\
\hline Total & 100,0 & 100,0 & 100,0 \\
\hline $\mathbf{N}$ & 262 & 111 & 373 \\
\hline
\end{tabular}


Tabela 9

Divisão do Cuidado com as Crianças segundo o Sexo

\begin{tabular}{|c|c|c|c|c|c|c|c|c|}
\hline SEXO & RESPOSTA & $\bar{A}$ & $\mathrm{~B}$ & $\mathrm{C}$ & $\mathrm{D}$ & $\mathrm{E}$ & $\mathrm{F}$ & G \\
\hline \multirow{9}{*}{ MulHer } & Sempre eu & 67,9 & 68,0 & 56,6 & 45,6 & 61,6 & 60,5 & 55,7 \\
\hline & Geralmente eu & 18,3 & 16,5 & 17,5 & 16,9 & 15,7 & 15,7 & 18,7 \\
\hline & Juntos & 3,9 & 6,0 & 14,7 & 26,0 & 16,5 & 15,4 & 9,9 \\
\hline & Geralmente meu cônjuge & 1,2 & 1,5 & 1,6 & 4,5 & 0,8 & 2,7 & 2,6 \\
\hline & Sempre meu cônjuge & 0,9 & 0,6 & 1,3 & 0,3 & 0,6 & 0,9 & 0,7 \\
\hline & Outra pessoa família & 7,2 & 7,5 & 8,4 & 6,6 & 4,8 & 4,8 & 12,5 \\
\hline & Outros & 0,6 & - & - & - & - & - & - \\
\hline & Total & 100,0 & 100,0 & 100,0 & 100,0 & 100,0 & 100,0 & 100,0 \\
\hline & $\mathrm{N}$ & 333 & 334 & 320 & 331 & 357 & 332 & 273 \\
\hline \multirow{9}{*}{ Номем } & Sempre eu & 5,1 & 5,4 & 4,9 & 4,0 & 5,8 & 5,0 & 7,4 \\
\hline & Geralmente eu & 4,3 & 2,7 & 5,7 & 7,0 & 3,4 & 3,1 & 6,0 \\
\hline & Juntos & 16,8 & 19,9 & 30,5 & 54,9 & 36,4 & 34,5 & 29,2 \\
\hline & Geralmente meu cônjuge & 33,2 & 32,2 & 25,2 & 11,0 & 22,3 & 24,5 & 21,3 \\
\hline & Sempre meu cônjuge & 32,8 & 33,3 & 24,4 & 16,1 & 25,8 & 28,4 & 25,5 \\
\hline & Outra pessoa família & 7,4 & 6,5 & 9,3 & 6,6 & 5,8 & 4,6 & 10,2 \\
\hline & Outros & 0,4 & - & - & 0,4 & 0,3 & - & 0,5 \\
\hline & Total & 100,0 & 100,0 & 100,0 & 100,0 & 100,0 & 100,0 & 100,0 \\
\hline & $\mathrm{N}$ & 256 & 261 & 246 & 273 & 291 & 261 & 216 \\
\hline \multicolumn{2}{|c|}{ Total Geral (N) } & 691 & 595 & 566 & 604 & 648 & 593 & 489 \\
\hline
\end{tabular}

Questões - Na sua casa, quem tem a responsabilidade de:

A - vestir e dar banho?

$\mathrm{B}$ - dar comida?

C - acompanhar as atividades escolares?

D - brincar?

E - levar ao médico?

$\mathrm{F}$ - colocar para dormir?

$\mathrm{G}$ - levar e pegar na escola? 


\section{Anexo 2}

\section{Quadro 1}

\section{Correlação entre os Três Índices, segundo Sexo do Respondente}

\begin{tabular}{|c|c|c|c|c|c|}
\hline \multicolumn{3}{|l|}{ Sexo } & MORAL & MODERN & PRATICA2 \\
\hline \multirow{9}{*}{ Masculino } & \multirow{3}{*}{ MORAL } & Correlação de Pearson & 1,00 & $0,307^{* * *}$ & $-0,023$ \\
\hline & & Significância (2-caudas) & 0,000 & 0,000 & 0,726 \\
\hline & & $\mathrm{N}$ & 809 & 654 & 242 \\
\hline & \multirow{3}{*}{ MODERN } & Correlação de Pearson & $0,307^{* * *}$ & 1,000 & $0,141^{*}$ \\
\hline & & Significância (2-caudas) & 0,000 & 0,000 & 0,043 \\
\hline & & $\mathrm{N}$ & 654 & 731 & 208 \\
\hline & \multirow{3}{*}{ PRATICA2 } & Correlação de Pearson & $-0,023$ & $0,141^{*}$ & 1,000 \\
\hline & & Significância (2-caudas) & 0,726 & 0,043 & 0,000 \\
\hline & & $\mathrm{N}$ & 242 & 208 & 272 \\
\hline \multirow{9}{*}{ Feminino } & \multirow{3}{*}{ MORAL } & Correlação de Pearson & 1,000 & $0,344^{* *}$ & $-0,067$ \\
\hline & & Significância (2-caudas) & 0,000 & 0,000 & 0,289 \\
\hline & & $\mathrm{N}$ & 820 & 674 & 254 \\
\hline & \multirow{3}{*}{ MODERN } & Correlação de Pearson & $0,344^{* * *}$ & 1,000 & 0,088 \\
\hline & & Significância (2-caudas) & 0,000 & 0,000 & 0,164 \\
\hline & & $\mathrm{N}$ & 674 & 768 & 250 \\
\hline & \multirow{3}{*}{ PRATICA2 } & Correlação de Pearson & $-0,067$ & 0,088 & 1,000 \\
\hline & & Significância (2-caudas) & 0,289 & 0,164 & 0,000 \\
\hline & & $\mathrm{N}$ & 254 & 250 & 305 \\
\hline
\end{tabular}

*Correlação é significativa a um nível de 0,05 (2-caudas).

***Correlação é significativa a um nível de 0,01 (2-caudas). 
Quadro 2

Relação entre Sexo, Percepção de Justiça na Participação do Trabalho Doméstico e Horas Dedicadas ao Trabalho Doméstico

\begin{tabular}{|c|c|c|c|c|c|c|c|}
\hline \multirow[b]{2}{*}{ SEXO } & \multirow[b]{2}{*}{ RESPOSTA } & \multirow[b]{2}{*}{$\mathrm{N}$} & \multirow[b]{2}{*}{ MÉDIA } & \multirow{2}{*}{$\begin{array}{l}\text { DESVIO- } \\
\text { PADRÃO }\end{array}$} & \multirow{2}{*}{$\begin{array}{c}\text { ERRO- } \\
\text { PADRÃO }\end{array}$} & \multicolumn{2}{|c|}{ 95\% INTERVALO DE CONFIANÇA } \\
\hline & & & & & & $\begin{array}{l}\text { Limite } \\
\text { Mínimo }\end{array}$ & $\begin{array}{l}\text { Limite } \\
\text { Máximo }\end{array}$ \\
\hline \multirow{4}{*}{ MASCULINO } & Mais que o justo & 31,00 & 21,03 & 21,366 & 3,837 & 13,2 & 28,87 \\
\hline & Justo & 188,00 & 18,93 & 21,758 & 1,587 & 15,8 & 22,06 \\
\hline & Menos que o justo & 117,00 & 12,46 & 18,065 & 1,67 & 9,15 & 15,77 \\
\hline & Total & 336,00 & 16,87 & 20,758 & 1,13 & 14,65 & 19,09 \\
\hline \multirow{4}{*}{ Feminino } & Mais que o justo & 218,00 & 39,44 & 22,552 & 1,527 & 36,43 & 42,46 \\
\hline & Justo & 238,00 & 35,2 & 21,3 & 1,381 & 32,48 & 37,92 \\
\hline & Menos que o justo & 15,00 & 29,53 & 18,45 & 4,764 & 19,33 & 39,75 \\
\hline & Total & 471,00 & 36,98 & 21,908 & 1,009 & 35,00 & 38,97 \\
\hline
\end{tabular}

ANOVA

\begin{tabular}{|c|l|r|r|r|r|c|}
\hline \multicolumn{2}{|c|}{ SEXO } & $\begin{array}{c}\text { SOMA DE } \\
\text { QuADRADOS }\end{array}$ & $\begin{array}{c}\text { GRAuS DE } \\
\text { LIBERDADE }\end{array}$ & $\begin{array}{c}\text { MÉDIA } \\
\text { QuADRÁtICA }\end{array}$ & F & SigNificÂNCIA \\
\hline MASCULINO & Entre grupos & $3.609,351$ & 2,000 & $1.804,676$ & 4,290 & 0,014 \\
\hline & Intragrupos & $140.082,100$ & 333,000 & 420,667 & - & - \\
\hline & Total & $143.691,500$ & 335,000 & - & - & - \\
\hline FEMININO & Entre grupos & 2912,573 & 2,000 & 1456,286 & 3,061 & 0,048 \\
\hline & Intragrupos & $222.659,300$ & 468,000 & 475,768 & - & - \\
\hline & Total & $225.571,900$ & 470,000 & - & - & - \\
\hline
\end{tabular}




\section{Anexo 3}

Variáveis que compuseram os indices: moral, percepções e práticas

\section{Moral}

É boa idéia viver junto antes de casar.

Castigo físico é uma forma aceitável de educar filhos. O homem deve punir a mulher em caso de infidelidade.

Ameaça é eficaz caso de adultério.

A mulher deve punir o marido em caso infidelidade. Mulher que faz aborto deve ser presa.

Aborto deve ser garantido em caso de risco de saúde para mãe.

Aborto deve ser garantido em caso de risco de anomalia fetal.

Aborto deve ser garantido em caso de risco de estupro.

Prevenção da gravidez é responsabilidade da mulher.

Preservativo deve ser usado por todos os casais.

Mulher casada deve fazer sexo com marido quando ele quiser.

Aborto é um direito da mulher.

\section{Percepções}

Mãe que trabalha fora tem melhor nível de vida.

Ter emprego é a melhor maneira de a mulher se tornar independente.

Ser dona de casa é tão gratificante quanto trabalhar fora.

A maioria das mulheres querem ter lar e filhos.

Vida familiar é prejudicada quando a mulher trabalha tempo integral.

Crianças sofrem mais quando a mãe trabalha.

Mãe que trabalha fora pode estabelecer relação carinhosa.

Homens e mulheres devem contribuir para renda familiar.

O homem deve ganhar dinheiro e a mulher deve cuidar da casa.

Homens devem assumir mais trabalhos domésticos. Homens deveriam cuidar mais das crianças.

Homens deveriam dividir igualmente as tarefas domésticas.
Renda ideal seria o homem ganhar mais do que a mulher.

Mulher deveria trabalhar depois de casar e antes de ter filhos.

Mulher deveria trabalhar se tiver filho pequeno.

Mulher deve trabalhar quando o filho caçula entrar escola.

Mulher deve trabalhar depois que filhos vão morar fora de casa.

Casados são mais felizes do que solteiros.

É melhor casamento ruim do que não estar casado. Quem quer ter filhos deve se casar.

$\mathrm{Pai} / \mathrm{mãe}$ sozinho pode criar filho tão bem quanto um casal.

É certo casal viver junto sem querer casar.

Divórcio é a solução para problemas de relacionamento.

Famílias devem receber auxílio financeiro para creche.

\section{Práticas}

Lava e passa roupa.

Faz pequenos consertos.

Cuida dos familiares doentes.

Compra comida.

Limpa a casa.

Cozinha.

Lava os pratos.

Vai ao banco/paga contas.

Quem decide como educar os filhos.

Quem decide as atividades do fim de semana.

Quem decide comprar coisas grandes para casa.

De quem é a responsabilidade de vestir e dar banho.

De quem é a responsabilidade de dar comida

De quem é a responsabilidade de acompanhar as atividades escolares.

De quem é a responsabilidade de brincar.

De quem é a responsabilidade de levar ao médico. De quem é a responsabilidade de pôr para dormir.

De quem é a responsabilidade de levar ou pegar na escola. 


\section{GÊNERO E A DISTÂNCIA ENTRE A INTENÇÃO E O GESTO}

Clara Araújo e Celi Scalon

Palavras-chave: Gênero e Família; Trabalho doméstico; Mulher e Trabalho

Neste artigo analisamos as percepções de homens e mulheres a respeito da conciliação entre trabalho pago e família, tomando como referência as relações de gênero. Com base nos resultados de um survey realizado no Brasil em 2004, procuramos investigar se há correspondência entre percepções mais ou menos igualitárias em relação ao gênero e atitudes mais compartilhadas no cotidiano do trabalho doméstico. Procuramos, também, identificar qual o peso e em que medida diferentes fatores - culturais, socioeconômicos e demográficos - são relevantes para a percepção de relações conjugais mais compartilhadas e simétricas nos valores e em certas práticas cotidianas.

\section{THE GENDER AND THE DISTANCE BETWEEN INTENTION AND ACTION}

Clara Araújo e Celi Scalon

Keywords: Gender and family; Household work; Women and labor market.

This paper analyses the perceptions of men and women on the compatibility between paid jobs and family, from the standpoint of gender relations. Based upon the results of a survey carried out in Brazil in 2004, it is examined whether there is a rapport between more equalitarian perceptions regarding gender and more shared attitudes regarding household work. There is also an attempt to identify the weight and the extent to which various factors (e.g. cultural, socioeconomic, and demographic) are relevant to the existence of values and routine practices that entail the perception of more balanced and symmetrical marital relations.

\section{GENRE ET DISTANCE ENTRE L'INTENTION ET LE GESTE}

\author{
Clara Araújo et Celi Scalon
}

Mots-clés: Genre et famille; Travail domestique; Femme et travail.

Dans cet article, nous analysons les perceptions des hommes et des femmes à propos de la conciliation entre le travail rémunéré et la famille, en prenant comme référence les rapports entre genres. Sur la base de résultats d'une enquête réalisée au Brésil en 2004, nous avons recherché l'existence d'une correspondance entre les perceptions plus ou moins égalitaires par rapport au genre et aux attitudes qui sont davantage partagées dans le quotidien du travail domestique. Nous avons également cherché à identifier le poids et dans quelle mesure les différents facteurs culturels, socio-économiques et démographiques sont importants pour la perception de relations conjugales davantage partagées et symétriques dans les valeurs et par rapport à certaines pratiques quotidiennes. 